\title{
WHY EVERY MUSEUM IS REALLY A MUSEUM OF SOCIAL HISTORY
}

\section{Kenneth Hudson}

For some years, I taught groups of American high school students, who came over to London for four months in order to broaden their experience. They were all about 20 years old and they lived in various parts of the United States. I shared the job of teaching them with three or four other people. Our task, in the words of our contract, was 'to expose them to an exotic culture', that culture, broadly speaking, being the one to be found in Britain, and it must indeed have appeared highly exotic to these young men and women, most of whom had never been outside America before.

I always made a point of taking them to the National Portrait Gallery in London, partly for selfish reasons - I love portraits - and partly because it provides a very good introduction to English history. You are surrounded by men and women who made English history. Hundreds and hundreds of them are there on the walls looking at you as you walk around looking at them. I happen to be particularly fond of the 18 th century. I think it means more to me than any other century, so, because I had to choose, we went straight to the 18 th and early 19th century galleries and spent most of our time there.

My method here, as in the other museums to which I took them, was to hold what I called a clinic. I would stand in the middle of the floor and tell my stu- dents to stroll about looking at the pictures and when they found something which particularly interested them to call me over. A group would then form around the two of us and we would have a miniseminar on the spot. On one occasion, a bright and bubbly girl shouted out - these young Americans have few inhibitions 'Hey, come here, Professor, I've got a big question here'. I made my way towards her and she wasted no time before coming to the point - 'Why have all the people in these portraits got double chins?'

'Ah', I said, 'you've turned up something very, very important. Why do you think they've got double chins?' - 'I don't know', she answered, 'that's why I'm asking you.' I threw it back at her: 'Do you think they did really all have double 
chins or did the artists give them double chins?' - 'Why would they want to do that?' she asked me.

So I explained that England was changing fast in the 18 th century. A great deal of new money was being made out of trade, industry, colonisation and warfare, estates were being acquired and developed, dynasties founded, fine houses being built, both in the town and in the country, prudent marriages arranged, and the ranks of the aristocracy continuously extended. In such a fluid situation, it was important not only to be successful, but to be seen to be successful, and what better or more obvious proof of worldly success could there be than a double chin, a sure sign that one was prosperous, wellfed and contented. So a portrait painter could have no better way of pleasing his patrons than by giving them this badge of success - the double chin.

The group was clearly getting very excited about this, especially when I pointed out how the American face, as shown in portraits, began to change after the Civil War, when big fortunes in abundance were being made in America for the first time. The thin, ascetic, tortured face, the Abraham Lincoln face, was out and the plump, smooth, self-satisfied face of the industrial or banking tycoon was in.

But at this moment, our happy and productive discussion was temporarily interrupted. A middle-aged lady, who had no connection at all with our group, came over to me, blazing with anger and said, 'Sir, you are prostituting art.' - 'In what way?' I asked her. - 'With all this talk about double chins,' she shouted. It was a meeting of two cultures. Her culture believed that there was something sacred cal- led art and that one had a duty to keep it pure and clean, free from unworthy and unnecessary outside associations. My culture insisted that the purpose of a work of art was to stimulate and anyone looking at it must be free to allow the mind and the emotions to move in whatever direction they pleased. No two people see a painting or a piece of furniture in exactly the same way. They bring different interests, different prejudices, different attitudes and different knowledge to it and consequently they are affected in a different manner by it. There is no correct, officially approved and certified art historian's way of seeing it, although it is certainly true that the more one knows about the world in which, say, a portrait was created, the more and the richer the pleasure one is likely to obtain from looking at it.

But this is true of any field of human activity. I know a great deal about horticulture, so that a visit to a fruit farm or a vegetable-growing enterprise is a rewarding experience for me and nothing about football or ice-hockey or horse-racing, so that I understand hardly anything if I should happen to see these things on television. Ignorant people cannot be connoisseurs, but not infrequently an outsider will discover an aspect of this or that pursuit which has been of little or no interest to the aficionado. He may observe, for instance, that it is rare in England for a professional footballer or flat-race jockey or boxer to have a middle-class background and equally rare to come across a working-class actor. The expert does not think in these terms. For him, the performance is everything.

The American girl at the National Portrait Gallery noticed the double chins 
precisely because she was not an art expert. Put another way, she had not been trained to ignore them. She was looking at the people in the portraits with an innocent eye and to the innocent eye, the child's eye, everything is potentially interesting and equally significant. To her, these 18 thcentury men and women, shown in the way the artists wanted, were essentially the same as the people she might see in a restaurant or in the Metro. To comment on them was to make a social observation. When the group moved into the next gallery, where the portraits were of early 19 th-century people, it was immediately obvious to her and to all the others that the double chins had disappeared. I explained why. Success no longer had to be expressed in terms of plentiful food and drink. The range of important and influential people in British society had become much wider. It now included scientists, engineers, industrialists and practical people of all kinds. Many of them were religious non-conformists and had comparatively ascetic habits. The double chin was not a symbol which was likely to appeal to their style and ambitions.

I would consider it perfectly normal and sensible to be interested in anything which a portrait or any other kind of painting might show. Let us consider the possibilities. They might include clothes, hair, architecture, dogs, furniture, horses and carriages, food and drink, jewellery, farm crops and animals - the list is neverending. Who is to say what should or should not be interesting? Would it be 'prostituting art' to talk about what a person in a portrait was wearing? I would go further, and say that for every member of the general public whose main interest is in the technique and style of a painting, at least a hundred are chiefly attracted by what the picture shows, by the clues it provides to life in the past. I see nothing in the least wrong about this. I believe that art should be about something. The quality and individuality of the work and of the artist lies precisely in how and how well that 'something' is interpreted and presented. Why a particular subject was chosen, why it was dealt with in this or that way and the decisions an artist had to take in order to earn a living and survive all these are facts of social history quite as much as of art history. And contemporary art is continuously in the process of becoming social history.

But let us move to a completely different kind of museum, the natural history museum. Once again, I think a concrete example will help. In the north-west of England, in a favourite tourist area known as the Lake District, there is a town called Kendal. Twenty years ago Kendal had a municipal museum which was fairly typical. It had been established at the end of the 19 th century and it contained the usual mixture of archæology, natural history and undistinguished pictures. The municipality no longer wanted to have the responsibility of running it and handed it over to a foundation which already had a very successful, modern museum elsewhere in the town. The curator of this museum, who had progressive ideas, was faced with a difficult problem. The former municipal museum obviously had to be completely reorganised and modernised, but there was very little money with which to do the job. Eventually, solutions were found for everything but the natural history 
6 department, which consisted mostly of stuffed birds and animals from all over the world, with no particularly local interest. For a long time the curator thought that the best and probably the only way of coping with this collection was to get rid of it, to clear it out of the building and to burn it, but then she had a much better idea. She noticed that nearly all the exhibits had been presented to the museum by one man, a major in the army, whose home was in Kendal. His great passion had been to go round the world shooting wild creatures. He did this for many years and presented the finest of the casualties, stuffed and mounted, to the museum in his home town.

The curator's answer to her problem was very brilliant. She simply put a portrait of the shooting major in the gallery and made him the centre of the exhibition. This, she told the public, is how the British upper classes used to be. They had the money, the temperament and, because of the British Empire, the opportunity to travel from country to country killing things. They had nothing better to do. Hunting, shooting and fishing were the most prestigious male pursuits within the class. They gave it cohesion and a set of values.

So, by a simple act of re-interpretation, what had previously been a natural history gallery became a social history gallery as well. No doubt the curator was criticised for this and quite possibly accused of 'prostituting natural history', much as I had been of 'prostituting art' in the National Portrait Gallery. But, so far as the critics were concerned, what exactly was the nature of the curator's crime? In order to answer this question, one has to travel back a little way into the history of both museums and the academic world.

It is a curious feature of modern civilisation, a post-Victorian perversion, that the highest prestige should go to specialists, the more extreme the specialisation, the greater the prestige. The specialists, of course, are the people who know more and more about less and less, the people who have the capacity and the temperament to turn an increasingly brilliant light on an increasingly minute part of human knowledge and experience. This, we are told, is the only way in which the frontiers of knowledge can be pushed forward, by concentrating on a very small area and exploring it in extreme depth and detail. I doubt very much, however, if this has any great relevance to public museums, which from their nature, cannot be expected to cater for extreme specialists. They may in time digest and interpret the work of these specialists and do what they can to make it intelligible to the general public. But the art of popularisation must necessarily bring about certain changes. The broad brush cannot achieve the same results as the fine brush, but it should aim at moving the mind and the emotions in the same direction. Popularisation and prostitution are not synonymous.

It makes me sad to observe that the most revered scholars nowadays, the scientists with the highest reputation, are those with the greatest ability to exclude what does not relate directly and immediately to their own chosen field of study. This is not an attitude with which I have much sympathy or patience. I suppose this is to some extent a matter of temperament. I have never found it possible to separate 
one field of mental activiry from another, to consider life in terms of academic subjects. I suppose this is why I have never been really interested in science. Even when I was at school, I found its disciplines restricting. I have always moved more easily in the worlds of history and literature, in which each discovery and association is permitted to stimulate another. I admit to being an intellectual anarchist and anarchists, I have been told, make poor scientists. I have never, thank God, been condemned to live and work in a one-party state. I doubt if I should have survived for very long in one. I resent being told what I should and should not think.

But now and again I have found myself in situations where an attempt has been made to condition my thinking and I have been able to test my reactions. Some years ago, for instance, I went on a cruise to the Greek islands and the Middle East, arranged by a body called the Hellenic Travellers Association. It was exceptionally well organised, with plenty of shore excursions. The ship was Turkish and had a Turkish crew, but we were not supposed to notice that. For the two weeks of the cruise, we were officially all Hellenists, devoting our waking hours to a place-byplace study of the contribution made by the ancient Greeks to the development of European civilisation. Our guides were highly educated Greek ladies and for two weeks they never ceased to remind us of our duty, which was never to allow our attention to wander away from the Greek achievement. Anything the Romans might have done in the region was trivial and irrelevant and unworthy of our attention. Enquiries about crops growing in the fields, local occupations, houses, churches, mosques were largely disregarded.

To begin with, I found all this profoundly irritating, but after a while irritation turned into fascination, as I began to understand better how the academic mind works. No doubt a group of guides hired to draw our attention to the legacy of ancient Rome would have behaved in a very similar way, apparently oblivious of the fact that it is precisely the mixture of cultures, past and present, which makes the whole Mediterranean region so fascinating.

I believe that the mind functions most effectively when it is free to wander where it pleases, coming to rest from time to time on a piece of information which demands detailed attention. The best museums, in my opinion, are the ones which encourage this attitude. The worst, on the other hand, demand the right to tell the visitor what he should see and in what order and what he should learn from each object. One must not and cannot attempt to condition people's minds in this way. The method is doomed to failure, simply because it is not possible to tell people what to think and to be obeyed. Museums are rooted in objects and the range of thoughts and emotions produced by an object is almost infinite, simply because no two human beings have had the same experiences.

This is what I mean when I say that all museums, of whatever kind, are necessarily and inevitably museums of social history. The public reaction to their exhibits is determined to a greater or lesser extent by the personal history and beliefs of individuals, that is, by associations. No museums exists in a social vacuum or in a 
8 vacuum of ideas. Each visitor arrives with a personal and family background and each object on display is surrounded and imbued with the beliefs, opinions and prejudices of the person who selected it, put it in position and attempted to interpret it. The interaction of these two sets of attitudes produces what one might call the museum situation and it is in this sense that every museum, of whatever kind, is a museum of social history. It represents the interplay of the thoughts and feelings of the people who created it and the people who come to see it, and this interplay is inescapably socially conditioned.

Socially conditioned may also mean sexually conditioned. We do not have to assume that both sexes respond to the same museum or exhibition in the same way. I think it is certain that men and women, broadly speaking, react very differently to military museums and costume museums, for example, and I suspect that the same might be true for other types of museum as well, although it is rare, in my experience, to find visitor-research surveys which attempt to discover this kind of information. The matter is probably quite complicated, since military museums in all countries are nearly always planned and run by men and costume museums by women. It is not at all impossible that a military museum organised by a woman and a costume museum by a man would achieve a completely different pattern of visitors and, I believe, a different emphasis. The costume museum would pay more attention to the cost of clothes and the military museum would almost certainly place armies and wars much more within their social context. At present, the history of costume tends to be almost entirely a matter of materials, style and technicalities and the history of armies and navies has nothing to say about the economics of warfare or the social background of soldiers and sailors. Yet for a museum to present either of these aspects of human life and behaviour as if they had nothing to do with money or the life of the community is clearly absurd and a change of policy is long overdue.

Clothes and the materials which go into them have to be made and, no matter what the economic system, this has always provided considerable employment. It is not merely a matter of style and design. The objects which appear in displays in costume museums are merely the tip of an economic iceberg, the results of a process, not the process itself. Looked at from this point of view, it is absurd to separate a textile museum from a costume museum.

The same kind of argument applies to a military or naval museum. Armies, navies and air forces exist in order to fight wars. They have to be paid for by the citizens of the countries to which they belong and, in one way or another, they provide employment for large numbers of people. They are not self-financing, autonomous bodies, but organisations which form part of the social, economic and political structure of the nation. How their personnel is recruited, disciplined and equipped and how their weapons, munitions, uniforms, transport and food is paid for is of the deepest concern to everyone. These things are authorised and financed by governments and are woven into the fabric of the states for which they are responsible. In order to remind visitors to military museums of this fact, it might be useful to 
put a price ticket on a selection of objects, saying how much a gun, a bullet, an aeroplane or a pair of boots actually cost at the time when it was made and what had to be paid for a loaf of bread or six eggs at the same date. It would be helpful to adopt the same procedure in the case of items in a costume collection, so that a dress, fashionable or otherwise, could be slotted realistically into the everyday life of the period when it was made and bought.

Every kind of museum collection has social and economic links of some kind. There is nothing scientific about displaying such collections in a vacuum. To do so involves removing one or more dimensions from them, weakening their power to interest and excite and, in effect, turning them into something else. Consider the social dimensions of a work of art. At any period, the person who makes it has to support himself, to eat and house himself, to undergo some form of training, to find and probably buy materials, to discover and please patrons and customers. The production of a work of art is an intensely social process.

So, too, is art appreciation. Visitors to an art gallery today who stand in front of, say, a Rembrandt or a Cézanne, cannot be affected by it in quite the same way as their predecessors of fifty or a hundred years ago. Their own world is not the same. Political and social thinking are very different, ambitions and fears have changed, the complexity of life has increased, the relation between man and nature is not the same, the old class structure has cracked and largely disappeared. If, like so much of medieval and Renaissance art, the subject and imagery of a painting is basically religious, most modern people are unable to understand it. They know little or nothing of either the Bible or of religious symbolism. They are religious illiterates. Their society no longer values these things.

An archaeological collection is a museum of social history on two quite different levels. The material in it represents the thoughts and activity of a society which no longer exists. It has been brought together in order to provide a means of exploring and studying that society. But the process of investigation is itself socially conditioned. Each generation of archæologists has its own limitations, its own prejudices, its own fixed ideas and these in turn are communicated to museum visitors. Our own concepts of Greek or Roman life, or of primitive societies are very different from those held by our fathers and grandfathers. The number of people able to read a Greek or Latin text has been steadily declining for more than half a century, so that the inscription on a Roman altar or memorial tablet is considerably more exotic now than it was before the First World War.

As the world changes and the aims and content of education change, so the relationship between museum visitors and museum displays becomes different. This is particularly true, perhaps, of natural history, science and technology. Today, unlike a hundred years ago, the proportion of Europeans living in a rural environment is very small. The majority of people in Germany, Italy or whichever other European country one selects, no longer see and hear wild birds and animals in their natural environment every day. They cannot identify even the most common trees and plants, walk very little and 
10 take most of their exercise in artificial ways, grow, rear, catch and kill none of their own food and often appear to regard the countryside as a kind of zoo. But, paradoxically, this detachment from rural surroundings has been combined with an increasing concern to safeguard nature from destruction. We strive to protect what we fear we are about to lose.

The result has been what might be called the politicisation of nature, a broadly based ecological movement which is concerned to discover and unmask the enemies of our planet, the organisations which are indifferent to its welfare and which pollute and exploit it for their own profit. In such an atmosphere, a new concept of 'normality' has developed, in which every living object, man included, becomes an endangered species and food animals and birds are grossly maltreated for the sake of financial gain. It consequently becomes increasingly difficult to view living creatures dispassionately. Fifty years ago, visitors to a zoo were able to view the exhibits without questioning the right of the zoo to exist. It is not easy to do so today, when man's claim to be superior to the rest of creation is more and more disputed. In the 19th century, few people would have been inclined to argue that zoos were not entitled to acquire wild animals and birds which had been trapped for the purpose, but nowadays this point of view is frequently put forward. When I was at school before the Second World War, I never remember anyone noting and complaining that the exhibits in a natural history museum had to be shot before they could be displayed, but such an attitude is almost normal today, especially among young people.
A museum cannot exist within a social and historical vacuum. It is part of the culture of its time and that culture is continuously changing. This means that the meaning of the same museum exhibit is not the same as it was twenty, fifty, a hundred years ago. It is becoming different with every generation, so that the chances of a display or a text organised by someone aged 50 being wholly or partly misunderstood by someone aged 20 or 30 are quite considerable. I doubt if this was true to the same extent before the Second World War, when values and standards were more stable.

To have travelled in trains hauled by steam locomotives means that one must now be at least 30 years old and probably nearer 40 . For anybody younger than this, a steam locomotive in a museum lacks the personal associations which make it completely real - the characteristic sounds and smells, the smoke and the dirt, the feeling of a machine being a living creature, which does not exist with an electric or diesel train. It is also difficult to communicate to anyone who has not experienced it directly how normal train travel was before mass ownership of cars made serious competition possible. In the same way, a motorcar from the 1920 s or 1930 s, shown in a museum, is not the same kind of object as one from the 1960s or 1970s. The difference is not simply in technology or appearance. The pre-war car was one of relatively few manufactured each year. It was sold to the members of a social élite. The more recent examples belong to the period in which both the ownership of motor vehicles and the ability to drive them had become more general and included the members of both sexes. The older 
car was made and used at a time when there was no reason to feel guilty that its emissions were polluting and poisoning the atmosphere, whereas by the 1970 s, if not the $1960 \mathrm{~s}$, the idea of the car-as-criminal was receiving a great deal of publicity.

In making this kind of distinction, in insisting on the dimension of social history which is possessed by every museum object, I am not, of course, advocating anything so foolish or so boring as that museums have a duty to make this explicitly clear in every exhibition they organise. To do so would be as tedious and as self-defeating as to preach the truth and validity of Marxism-Leninism through the museums of the former Communist countries. Understandably, the visitors simply switch off. What I believe is required is something much more subtle and more useful - to plant the occasional clue, the well-timed shock, which will remind visitors that museum objects exist as bridges between the past and the present and that our ancestors had attitudes different from our own. If this is not done, much of the cultural value of a museum is thrown away. At present there is a tendency to believe that the construction of such bridges is the business of specialist museums, historical museums, and that all the rest are entitled to ignore it. I believe this is nonsense. The cultivation of an historical sense in all fields is the mark of a civilised person. A truly civilised person cannot confine his feeling for history to certain specific areas. It will operate instinctively in everything he does.

What surprises me is the number of museum specialists who deny that what they have to show has any connection with social history at all. They appear to that it can and should be judged by its own standards. This means, for example, that yesterday's furniture or clothes were not bought or used by real people and that there was no connection between jewellery and wealth, elephants and the ivory trade or poverty and disease. It means, too, that the people, costumes, buildings and domestic equipment that one sees in paintings are of small importance by comparison with the techniques which produced the picture. I consider this attitude to be perverted. It is specialisation for the sake of specialisation.

I began this talk with a story and I should like to end with another one. A friend of mine is the director of a large national museum of science and technology. For two years or more he has been trying to decide what his museum is for, what is its main purpose. Broadly speaking, museums such as his fall into two groups. The earlier ones - the Deutsches Museum in Munich, the Technisches Museum in Vienna, the Science Museum in London, and so on - are what one might call pure technology, all machines, processes and engineers, but no social context. The later examples - Rüsselsheim, Essen, Wuppertal and now Mannheim - bring technical history and social history together, in order to show how one has influenced the other. I remember, many years ago, talking to one of the senior staff in the Deutsches Museum - he later went to Berlin, to create the new museum of technology and transport there - in the section of the Museum which is devoted to tunnels and tunnelling. There are a number of excel- 
12 lent displays showing the tunnels constructed under the Alps between Italy and Switzerland. Each provides the name of the engineer in charge and a mass of technical details, like the total length and the number of cubic metres of rock that had to be excavated, but of the men who actually carried out the work, absolutely nothing. 'To look at these models' said the curator, 'you'd never realise, would you, that the people who dug the tunnels were poor Italians, who were paid very little for their work, who lived in the tunnels for months and who were injured and killed in their dozens by explosions and rock falls?' When I asked him why visitors weren't given these details, he said, 'Oh, this museum gers a lot of money from industrial sponsors and they don't like facts like that. They think they're bad for the image of industry.'

And at this point we return to my friend, who's trying to decide what his big museum of science and technology is for. This museum, I ought to explain, is one of the pioneering breed, technology for the sake of technology, with little or no social context in the atmosphere or presentation. Here, too, social history is felt to be politically dangerous and the sponsors would disapprove. For some time he told the world that his aim was 'to improve the public understanding of science', but, when it became evident that few people understood what this meant, if, indeed, it meant anything, he decided that his real aim ought to be 'to raise the prestige of the engineer'. But in order to do this, I insisted, 'you'll have to show how useful engineers have been to society, how they've changed the level and pattern of people's lives. And that would necessitate put- ting the engineers' achievements into their social context'. He resisted this idea very hard. 'Oh no,' he said, 'I shall assess what they've done from an engineering point of view.' At this point I gave up trying. It was like discussing evolution with someone who believed that the Book of Genesis was literally and 100 per cent true and that disbelievers should be burnt alive. Art for art's sake, engineering for engineering's sake, furniture for furniture's sake, and all this in the last decade of the second millennium. We should be able to do better than this.

Kenneth Hudson höll denna föreläsning den 3 april 1992 vid dåvarande institutionen för museologi vid Umeå universitet. 